1 ANALYTICAL SCIENCE

2 \& TECHNOLOGY

Vol. 25, No. 6, 339-344, 2012

\title{
Comparison of chemical and photochemical generation of hydrides in Se speciation study with HPLC-HG-ICPMS
}

\author{
Hana Ji and Yong-Nam Pak ${ }^{\star}$
}

Department of Chemistry Education, Korea National University of Education

(Received September 6, 2012; Revised October 22, 2012; Accepted November 14, 2012)

\section{HPLC-ICPMS를 이용한 셀레늄 화학종의 연구에서 화학적 및 광화학적 수소화물 발생법의 비교}

\author{
지하나 · 박용남 \\ 한국교원대학교 화학교육학과 \\ (2012. 9. 6. 접수, 2012. 10. 22. 수정, 2012. 11. 14. 승인)
}

\begin{abstract}
In this research, hydride generation in HPLC-ICPMS for the selenium speciation was investigated. Chemical and photochemical vapor generation techniques were compared for the effective generation of selenium vapour. $\mathrm{HBr} / \mathrm{KBrO}_{3}$ was used for the chemical reduction and a UV lamp was used for the photochemical reduction. It was found out that the photochemical reduction was more effective than the chemical reduction in all of selenium species studied. The optimum conditions for the generation of vapour are $0.4 \% \mathrm{KI}, 2.5 \%$ $\mathrm{NaBH}_{4}$, and $1.0 \mathrm{M} \mathrm{HCl}$. The enhancement factor using a photochemical hydride generation was from 6.3 to 16.7 times for inorganic and organic selenium species.
\end{abstract}

Key words: Se, Se speciation, hydride generation, photochemical reduction, HPLC-HG-ICPMS

\section{1. 서 론}

유도결합 플라즈마 질량분석법(ICP-MS; inductively coupled plasma-mass spectrometry)은 ng/g 혹은 그 이 하의 낮은 검출한계와 동위원소비의 측정능력 때문에 극미량 분석이 요구되는 여러 분야에서 널리 이용되 고 있다. 하지만 아직 몇 원소들에 대하여서는 더욱 높은 감도가 요구되며 동위원소비를 측정할 때에 공 존원소에 의한 매트릭스 간섭 현상이 나타난다는 단
점을 가지고 있다. 따라서 분리 기술을 이용하여 여 러 성분이나 화학종들을 분리한 뒤 민감하게 분석하 는 HPLC (High Performance Liquid Chromatography)ICPMS 방법이 유용하게 사용되고 있다. ${ }^{1,2}$ 이 외에도 모세관 전기영동(CE; capillary electrode) ${ }^{3-5}$ 기체 크로 마토그래피(GC; gas chromatography) ${ }^{6,7}$ 등의 분리기술 들이 ICPMS와 연결하여 화학종연구에 주요하게 쓰이 고 있다.

셀레늄은 생체 내 필수 극미량 원소이지만 과다 섭

$\star$ Corresponding author

Phone : +82-(0)43-230-3732 Fax : +82-(0)43-232-7176

E-mail : pakyn@knue.ac.kr 
취시 독성을 갖게 되고, 결핍시 질병을 유발하기 때문 에 인체에 적합한 적정량을 정확히 분석해야 한다. 셀 레늄의 분석에는 무기성 $\mathrm{Se}$ (selenate, selenite)과 유기성 Se (selenomethylselenocystein, selenomethionine, selenocystine)을 모두 포함하므로 다양한 형태로 존재하는 여러 셀레늄 화학종들을 분석할 때에는 HPLC-ICPMS 가 매우 유용하다. ${ }^{8}$ 또한, 시료중의 셀레늄의 량은 매 우 작은 경우가 많다. 따라서 극미량으로 존재하는 여 러 셀레늄 화학종들을 높은 감도로 분석하는 것이 필 요하다. 수소화물 발생법(HG; hydride generation)은 시료 용액을 기체형태로 전환시켜 감도세기를 증가시 킬 뿐 아니라, 매트릭스를 제거함으로 기질 방해로부 터의 해방, 시료의 점성 등에 의한 물리학적 간섭과 분광학적 방해 및 이온화 방해 등을 적게 받을 수 있 는 장점들이 있다. 따라서 수소화물 발생법을 HPLCICPMS에 도입하면 셀레늄의 분석은 더욱 효과적이 될 것이다.

수소화물 발생장치를 HPLC에 연결하여 ICPMS로 검출하는 HPLC-HG-ICPMS 방법은 HPLC에서 분리 되는 여러 셀레늄 화학종들을 증기로 전환시켜 검출 하므로 감도를 개선시킬 수 있을 것이다. ICPMS을 이용한 셀레늄의 분석에 $\mathrm{Br}$ 이 동중간섭할 수 있는데 ${ }^{9}$ $\mathrm{HPLC}$ 에서는 $\mathrm{Br}$ 이 셀레늄과 함께 용리될 수 있지만 $\mathrm{HG}$ 를 사용하면 $\mathrm{Br}$ 이 제거되어 정확한 분석과 동위원 소비의 측정이 가능하게 된다. Darrouzes와 Potin-Gautier 등 $^{10}$ 은 이온교환 크로마토 그라피에서 수소화물을 생 성시켜 검출한계의 개선과 $\mathrm{Br}$ 에 의한 간섭을 배제한 뒤 HPLC-ICPMS로 샘물에 있는 셀레늄을 민감하게 분석할 수 있었다. 감도개선은 약 3 배 정도로 높지 않 으나 $\mathrm{Br}$ 의 간섭배제가 효과적이었다.

하지만 모든 셀레늄화학종들이 다 수소화물을 발생 시키지는 않으며 발생효율도 다르다. 따라서 여러 화 학종들이 수소화물 발생장치에 도입되기 전에 이들을 연속적으로 $\mathrm{Se}^{4+}$ 로 환원시켜야 한다. 여기에는 마이크 로파를 이용한 방법 ${ }^{11,12}$ 이나 화학적인 방법과 광화학 적 방법 ${ }^{13-15}$ 이 사용될 수 있다.

광화학적 방법은 비교적 최근에 Sturgeon ${ }^{14}$ 에 의하 여 알려지기 시작했으며 원자흡수 분광법 또는 ICP$\mathrm{OES}^{15}$ 에 이용되었다. Simon 등 ${ }^{16}$ 은 주로 $\mathrm{HPLC}$ 에서 연속적으로 광화학적 환원을 통하여 셀레늄의 여러 화학종들의 수소화물들을 발생시킨 뒤 원자형광법으 로 검출하는 연구를 보고한 바 있다. 최근에 소개되고 있는 광화학적 수소화물 발생법은 화학적 방법에 비 하여 빠르며 화학시료의 소비가 적고 수소기체의 발
생이 적어서 플라즈마의 안정성이 높으며 전이금속의 방해가 적다고 알려져 있다. ${ }^{17}$

본 연구에서는 HPLC-HG-ICPMS에서 셀레늄화학 종들을 on-line 상에서 화학적으로 환원시키는 방법과 광화학적 방법으로 환원시키는 두 방법을 비교 연구 하고 최적의 수소화물 발생조건을 찾아내었다.

\section{2. 실험 및 방법}

셀레늄의 여러 화학종들을 HPLC (HPLC Model 626 dual pump, Alltech, USA)를 사용하여 분리시킨 다음 수소화물을 발생시키고 팔중극자 반응셀(Octopole Reaction Cell)이 장착되어 있는 ICP-MS (Agilent 7500ce, U.S.A.)를 사용하여 검출하였다. 컬럼은 역상 $\mathrm{RP}_{8}$ Symmetryshield $^{\mathrm{TM}}$ (Waters, U.S.A.)을 사용하였다. 수소 화물 발생장치는 상업용으로 제작된 장치 FIAS (Perkin Elmer, U.S.A.)를 사용하였다.

\section{1. 시약 및 시료}

시약과 시료의 제조는 환경적 오염을 최소화하기 위하여 clean booth내에서 진행하였다. 실험에 사용한 용기 및 기구는 진한 염산으로 산세척 후 탈 이온수 로 씻고 건조하여 사용하였다. 시약제조에는 $18.2 \mathrm{M} /$ $\mathrm{cm}$ 초순수(Millipore direct-Q system) 탈 이온수를 사용 하였다.

셀레늄 표준용액은 Sigma Aldrich사의 Sodium selenite $\left(\mathrm{Se}^{4+}\right)$, Sodium selenate $\left(\mathrm{Se}^{6+}\right)$, Se-methylselenocysteine (Se-M-C), Se-DL-methionine (Se-Met), L-Selenocystine (Se-Cys)를 각각 $100 \mathrm{ng} / \mathrm{g}$ 를 만들어 사용하였다. 용기 의 세척과 시료에 사용한 질산은 동우화인켐에서 구 입한 반도체급 시약을 사용하였다. 메탄올은 J.T. Baker사의 $99.8 \%$ 의 HPLC급 시약을 사용하였고 이온 쌍시약으로는 nonafluorovaleric acid를 사용하였다. 이 동상은 메탄올을 초순수 물에 넣어 $5 \%$ 로 묽히고 nonafluorovaleric acid를 $0.05 \%$ 되게 가한 뒤, 질산이나 $\mathrm{NaOH}$ 를 사용하여 $\mathrm{pH}$ 를 2.5로 조절하였다.

\section{2. 기기의 최적조건}

먼저 ICP-MS 기기의 최적 조건을 찾기 위하여 Agilent 회사의 tuning solution을 사용하였고 감도와 신 호대 잡음의 비가 크고 \% RSD 가 낮은 조건을 찾았다 . 충돌기체는 $\mathrm{He}$ 와 $\mathrm{H}_{2}$ 를 사용하여 비교하였고 이 때 표 준용액은 셀레늄 $10 \mathrm{ng} / \mathrm{mL}$ 의 표준시약을 이용하였다. ICPMS와 HPLC의 최적조건을 다음 Table 1 에 실었다. 
Table 1. Optimized experimental conditions for ICPMS and HPLC

\begin{tabular}{|c|c|c|}
\hline \multicolumn{3}{|c|}{ ICPMS } \\
\hline \multicolumn{2}{|l|}{ RF Power (W) } & 1560 \\
\hline \multicolumn{2}{|c|}{ Carrier Gas (L/min) } & 0.92 \\
\hline \multicolumn{2}{|c|}{ Makeup Gas (L/min) } & 0.10 \\
\hline \multicolumn{2}{|c|}{ Collision gas, $\mathrm{H}_{2}(\mathrm{~mL} / \mathrm{min})$} & 3.5 \\
\hline \multicolumn{3}{|c|}{ HPLC } \\
\hline Column & \multicolumn{2}{|c|}{$\begin{array}{l}\text { Symmetryshield }{ }^{\mathrm{TM}} \\
\mathrm{RP}_{8}(3.5 \mu \mathrm{m}, 4.6 \times 150 \mathrm{~mm})\end{array}$} \\
\hline Injection volume $(\mu \mathrm{L})$ & \multicolumn{2}{|c|}{50} \\
\hline Flow rate $(\mathrm{mL} / \mathrm{min})$ & \multicolumn{2}{|l|}{0.90} \\
\hline Mobile phase & \multicolumn{2}{|c|}{$5 \%$ Methanol (pH 2.5) } \\
\hline Ion-paring reagent & \multicolumn{2}{|c|}{$0.05 \%$ nonafluorovaleric acid } \\
\hline
\end{tabular}

\section{3. 실험 절차}

$\mathrm{HPLC}$ 에서 용리되는 셀레늄 화학종들은 수소화물 발생장치로 들어가기 전에 먼저 환원이 되어야 한다. 화학적 환원법에서는 $\mathrm{HBr} / \mathrm{KBrO}_{3}$ 를 용리액과 연속적 으로 혼합시킨 뒤 수소화물 장치로 들어가게 하였다

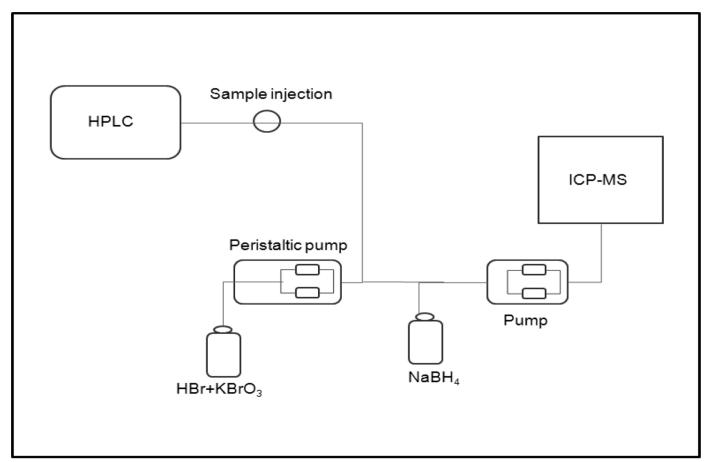

(a)

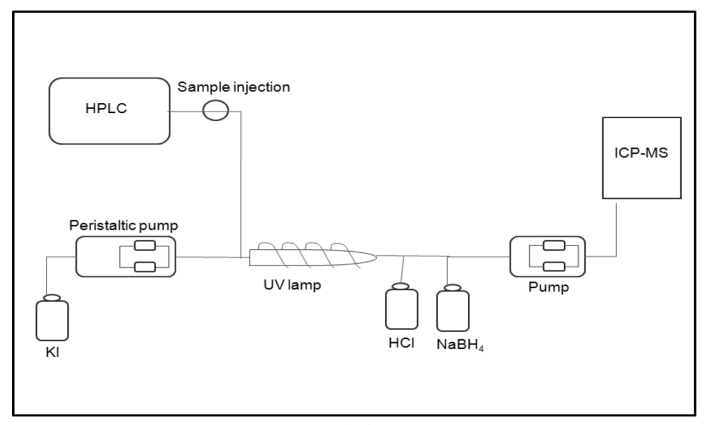

(b)

Fig. 1. Schematic diagram of the HPLC-HG-ICPMS for (a) chemical reduction method and (b) photochemical reduction method.
(Fig. 1(a)). 광화학적 방법(Fig. 1(b))에서는 HPLC 용 리액에 KI를 먼저 혼합시키고 반응코일을 통하여 일 정시간 동안 $\mathrm{UV}$ 를 쪼여 $\mathrm{Se}^{4+}$ 로 환원시켰다. 이 후 환 원된 셀레늄은 $\mathrm{NaBH}_{4}$ 와 혼합하여 수소화물 장치로 들어가 수소화물을 발생하고 기체생성물은 $\mathrm{Ar}$ 운반기 체에 의해 ICP-MS로 들어가게 된다.

\section{3. 결과 및 고찰}

본 실험 전에는 항상 기기를 최적화 하였다. $\mathrm{HBr} /$ $\mathrm{KBrO}_{3}$ 를 사용한 화학적 방법과 $\mathrm{UV}$ 를 사용한 광화학 적 방법에 대한 최적 조건들을 구하고 그 결과를 아 래의 Table 2에 실었다. 플라즈마에서 두 방법의 조건 들은 비슷하나, 운반기체와 흐름속도에 있어서 약간의 차이를 보이고 있다.

\subsection{HPLC-ICPMS를 사용한 셀레늄 종들의 분리}

먼저 $\mathrm{HG}$ 를 사용하지 않은 상태에서 셀레늄 종들의 분리정도와 신호 세기를 측정하였다(Fig. 2). ICPMS 의 신호는 ${ }^{77} \mathrm{Se}$ 가 사용되었는데 그 이유는 비록 신호 의 세기는 작지만 다른 동위원소들에 비해서 가장 작 은 동중간섭을 보여주기 때문이었다. 셀레늄 표준시료 $\left(\mathrm{Se}^{4+}, \mathrm{Se}^{6+}, \mathrm{Se}-\mathrm{Met}, \mathrm{Se}-\mathrm{Cys}\right.$, 그리고 $\left.\mathrm{Se}-\mathrm{M}-\mathrm{C}\right)$ 를 측정 하여 좋은 결과를 얻었는데 여기에서는 대표적으로 $\mathrm{Se}^{4+}$ 와 $\mathrm{Se}-\mathrm{M}-\mathrm{C}$ 만 나타내었다.

\section{2. 화학적 환원법을 사용한 HPLC-HG-ICPMS}

다음에는 HPLC에서 분리된 여러 셀레늄 화학종들 을 화학적으로 환원시킨 뒤에 수소화물 발생장치로 보내고 발생된 수소화물을 ICPMS로 측정하였다. 화 학적 환원제로서는 $\mathrm{HBr} / \mathrm{KBrO}_{3}$ 용액을 사용하였다. 여러 시약의 최적 농도를 구하여 본 결과, $\mathrm{HBr}$ 은 $47 \% \mathrm{wt} / \mathrm{v}, \mathrm{KBrO}_{3}$ 는 $1.5 \times 10^{-2} \mathrm{M}$, 그리고 $\mathrm{NaBH}_{4}$ 는 $0.5 \% \mathrm{wt} / \mathrm{v}$ 을 얻을 수 있었다.

Table 2. Optimum instrumental conditions for chemical and photochemical reductions for Se in HPLC-HG-ICPMS

\begin{tabular}{lcc}
\hline \hline & Chemical & Photochemical \\
\hline RF power (kW) & 1.6 & 1.5 \\
Carrier gas (L/min) & 0.92 & 0.6 \\
Makeup gas (L/min) & 0.10 & 0.6 \\
Collision gas (mL/min) & 4.0 & 3.5 \\
Reagent flow rate (mL/min) & $\mathrm{HBr} / \mathrm{KBrO}_{3} ;$ & $\mathrm{KI} ; 0.5 \mathrm{KCl} ;$ \\
& 1.1 & $0.3 \mathrm{NaBH}$; 0.4 \\
\hline
\end{tabular}




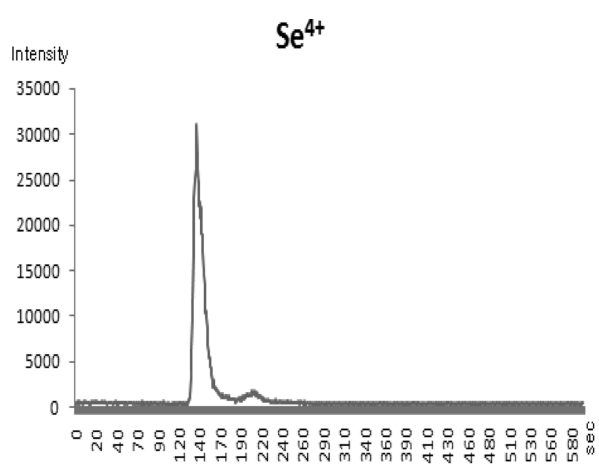

(a)

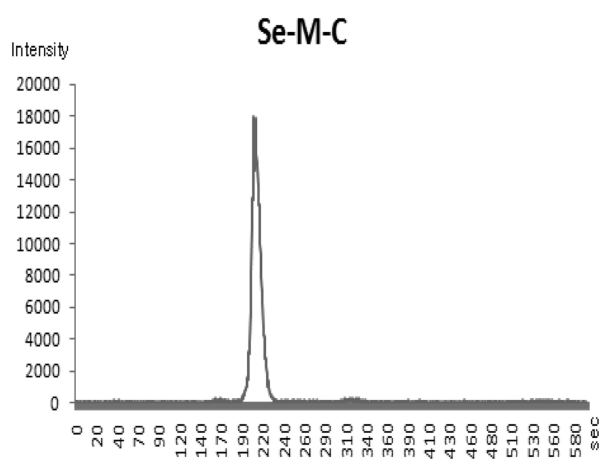

(b)

Fig. 2. Chromatogram of $\mathrm{Se}^{4+}$ (a) and $\mathrm{Se}-\mathrm{M}-\mathrm{C}$ (b) for HPLCICPMS $(100 \mathrm{ng} / \mathrm{g}, 50 \mu \mathrm{L}$ injection).

이 조건하에서 먼저 셀레늄 표준시료 $\left(\mathrm{Se}^{4+}, \mathrm{Se}^{6+}, \mathrm{Se}-\right.$ Met, Se-Cys, Se-M-C)를 측정하였다. HG를 사용하였을 때에 $\mathrm{Se}^{4+}$ 는 3.3 배 정도 신호세기가 커졌지만 $\mathrm{Se}^{6+}$ 는 측정되지 않았으며 Se-Met, Se-Cys, Se-M-C의 신호는 오히려 작아지는 것을 볼 수 있었다(Fig. 3). 즉, 화학적 인 환원법으로는 HPLC의 용리액내의 셀레늄 화학종들 을 효율적으로 환원시키지 못하는 것으로 보인다. 또한, $\mathrm{Se}$ 의 동위원소비를 측정해 보면 $\mathrm{m} / \mathrm{z} 80$ 과 82 에서 큰 오차를 보여준다. 이것은 ${ }^{79} \mathrm{Br}^{1} \mathrm{H}^{+}$과 ${ }^{81} \mathrm{Br}^{1} \mathrm{H}^{+}$의 생성으로 인한 것으로 보이며 화학적 환원제에서 사용되는 $\mathrm{Br}$ 이 $\mathrm{ICPMS}$ 의 충돌셀에서 반응하여 $\mathrm{BrH}^{+}$가 생성되는 것으 로 생각된다.

\section{3. 광화학적 방법을 사용한 HPLC-HG-ICPMS}

광화학적 환원을 용이하게 하기 위하여 먼저 용리 액에 $\mathrm{KI}$ 를 넣어주어 혼합시켜 주었다. $\mathrm{KI}$ 의 범위를 $0.1-0.5 \%$ 에서 살펴본 결과, $0.4 \%$ 에서 여러 셀레늄 화 학종의 신호세기가 높으며 안정된 결과를 보여 주었 다. 환원제와 산에 대한 최적농도를 구하기 위하여

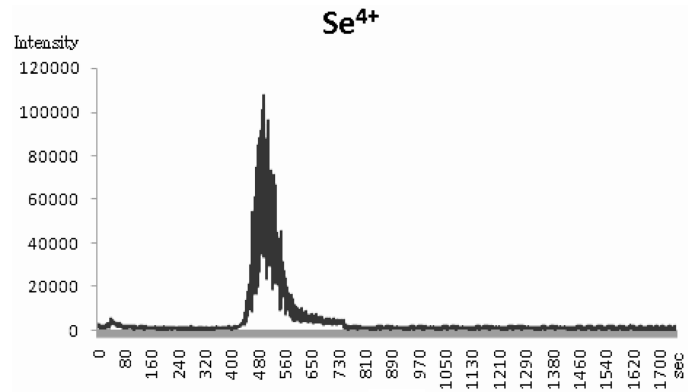

(a)

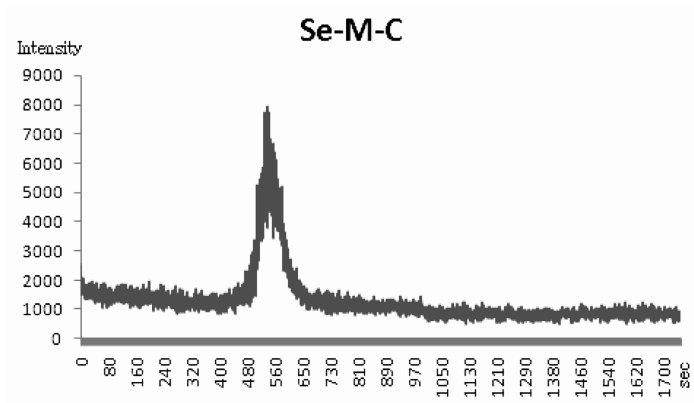

(b)

Fig. 3. Chemical reduction for $\mathrm{Se}^{4+}$ (a) and $\mathrm{Se}-\mathrm{M}-\mathrm{C}$ (b) in HPLC-HG-ICPMS.

$\mathrm{NaBH}_{4}$ 의 범위를 $0.5-4.0 \%$ 에서 살펴보았고 염산 농도 의 범위는 0.5-5 M에서 살펴본 결과, 비록 화학종에 따라 조금씩 감도가 달랐지만 가장 공통적인 최적조 건으로 $2.5 \% \mathrm{NaBH}_{4}, 0.4 \% \mathrm{KI}$, 그리고 $1.0 \mathrm{M}$ 의 $\mathrm{HCl}$ 을 얻었다.

광화학적 환원을 사용한 HPLC-HG-ICPMS의 결과 를 $\mathrm{Se}^{6+}$ 와 Se-M-C에 대하여 보여주었다(Fig. 4). 화학 적 환원에서는 나타나지 않았던 $\mathrm{Se}^{6+}$ 의 경우에도 신호 가 나타나고 있음을 보인다. 수소화물 발생법을 사용 하기 전과 비교하면 감도가 증가함을 알 수 있었으며 $\mathrm{Se}-\mathrm{M}-\mathrm{C}$ 의 경우에도 신호가 크게 증가하였다.

화학적 방법과 광화학적 방법에 의한 수소화물의 발생을 실험하고 신호의 증가비(HG 사용 시의 신호/ $\mathrm{HG}$ 사용하지 않을 때의 신호)를 비교하여 그 결과를 다음의 Table 3에 실었다.

화학적 환원의 경우, $\mathrm{Se}^{4+}$ 와 $\mathrm{Se}-\mathrm{M}-\mathrm{C}$ 를 제외하고는 수소화물 발생법에 의한 신호의 증가가 보이지 않았 다. 비록 신호는 약간 증가할 수 있지만 여러 화학시 약들을 사용함으로써 시료가 묽어져 농도는 감소하기 때문에 결과적으로 감도의 개선은 이루어 지지 못한 편이다. 반면에 광화학적 환원은 모든 셀레늄 화학종 들의 신호가 증가하였으며 Se-M-C의 경우에는 약 17 


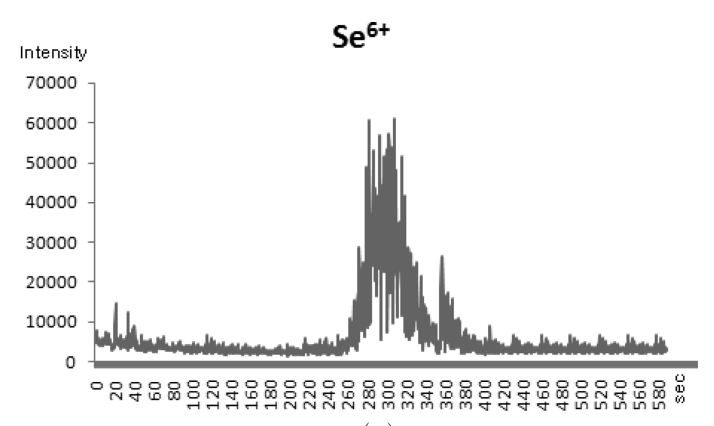

(a)

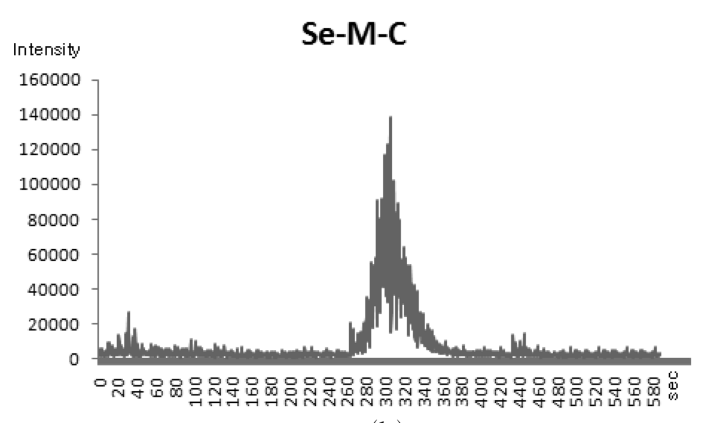

(b)

Fig. 4. Photochemical reduction for $\mathrm{Se}^{6+}$ (a) and $\mathrm{Se}-\mathrm{M}-\mathrm{C}$ (b) in HPLC-HG-ICPMS.

Table 3. Comparison of sensitivity enhancement for chemical and photochemical reduction of Se in HPLC-HGICPMS

\begin{tabular}{lccc}
\hline \hline \multicolumn{4}{c}{ Enhancement factor* } \\
\hline & $\begin{array}{c}\text { Chemical } \\
\text { HPLC-HG- } \\
\text { ICPMS }\end{array}$ & $\begin{array}{c}\text { Photochemical } \\
\text { HPLC-HG- } \\
\text { ICPMS }\end{array}$ & $\begin{array}{c}\text { Photochemical/ } \\
\text { chemical }\end{array}$ \\
\hline $\mathrm{Se}^{4+}$ & 4.87 & 12.8 & 2.63 \\
$\mathrm{Se}^{6+}$ & - & 6.30 & $\mathrm{NA}$ \\
$\mathrm{Se}-\mathrm{Met}$ & 1.09 & 10.0 & 9.17 \\
$\mathrm{Se}-\mathrm{Cys}$ & 1.19 & 14.7 & 12.4 \\
$\mathrm{Se}-\mathrm{M}-\mathrm{C}$ & 2.79 & 16.7 & 5.98 \\
\hline
\end{tabular}

*Peak area of ${ }^{77} \mathrm{Se}$ is used for calculation

NA; not able to calculate

배까지 증가하였다. 화학적 환원과 광화학적 환원의 신호의 증가비를 조사해보면 모든 화학종의 경우에 광화학적 환원이 월등한 감도의 증가를 나타내었고 Se-Met이나 Se-Cys을 보면 10배 정도 효율이 높음을 알 수 있다. 또한 매트릭스 간섭의 경우, 광화학적 환 원의 경우에는 $\mathrm{m} / \mathrm{z}$ 79에서 깨끗한 바탕을 얻을 수 있 음으로 보아 $\mathrm{Br}$ 의 간섭이 배제된 것으로 생각된다.
다만, 신호에서의 잡음이 $\mathrm{HG}$ 를 사용하지 않은 경우 와 비교해 보면 증가하였는데 이것은 수소화물 발생 법의 본질상 흐름의 변화에 대하여 매우 민감하게 반 응하기 때문이다. 또한 수소기체의 발생 및 격렬한 환 원반응으로 잡음이 증가하는 것으로 생각되며 무엇보 다도 용리액에서의 이온쌍 시약도 반응에 참여하는 것으로 생각된다. 따라서 역상보다는 이온교환 컬럼을 사용하는 것이 더 안정적인 신호를 얻을 것으로 생각 되며 이 부분에 대한 연구를 지속중이다.

\section{4. 결론 및 제언}

본 연구에서는 셀레늄 화학종의 분리분석에서 감도 를 증진시키기 위하여 HPLC-ICPMS에 HG를 연결하 여 연구하였다. HPLC-HG-ICPMS에서 광화학적 환원 을 이용한 셀레늄 분석의 최적 조건은 $\mathrm{NaBH}_{4}$ 의 농도 는 $2.5 \%, \mathrm{KI}$ 의 농도는 $0.4 \%$ 이며, $\mathrm{HCl}$ 은 $1.0 \mathrm{M}$ 이고 운반기체의 흐름속도는 $1.2 \mathrm{~L} / \mathrm{min}$ 이었다. 극미량으로 존재하는 여러 셀레늄 화학종들을 분석하는데 광화학 적 환원이 효율적이며 감도는 약 17 배 까지 증가 할 수 있었다. 화학적인 방법과 광화학적인 두 방법을 비 교할 때, 화학적인 방법은 감도의 개선이 적고 ${ }^{79} \mathrm{Br}{ }^{1} \mathrm{H}$ 의 영향을 받았지만 광화학적인 방법은 모든 원소에 대하여 감도의 개선이 잘 이루어 졌으며 $\mathrm{Br}$ 매트릭스 의 간섭까지 제거할 수 있음을 알 수 있었다.

현재 on-line HPLC-HG-ICPMS 환원의 경우 크로마 토그램을 보면 잡음이 심하며 피이크의 폭이 넓은데 좀 더 안정적으로 수소화합물기체를 발생시키는 연구 가 필요할 것으로 보인다. HPLC 이동상의 흐름속도 를 조절하여 잡음을 줄이고 무엇보다 현재 사용하고 있는 $\mathrm{C}_{8}$ 컬럼에서 이온교환 컬럼으로 바꾼다면 잡음 이 많이 줄어 들 것으로 기대된다. 광화학적 환원에 의한 연속적 수소화합물의 생성연구는 단지 셀레늄의 화학종연구 뿐 아니라 비소 및 다른 금속의 화학종 연구에도 폭 넓은 활용이 가능할 것으로 기대된다.

\section{감사의 글}

본 연구는 과학연구재단 일반연구(2012-0002946)의 지원으로 수행된 것으로 이에 감사드립니다.

\section{참고문헌}

1. C. Casiot, J. Szpunar, R. Lobinski and M. Potin- 
Gautier, J. Anal. At. Spectrom., 14, 645-650 (1999).

2. N. Jakubowski, R. Lobinskib and L. Moens, J. Anal. At. Spectrom., 19, 1-4 (2004).

3. J. A. Day, S. S. Kannamkumarath, E. Yanes, M. Montes-Bayo'n and J. A. Caruso J. Anal. At. Spectrom., 17, 27-31 (2002)

4. A. R. Timerbaev, Talanta, 52, 573-581 (2000).

5. J. W. Olesik, in 'Elemental Speciation: New Approaches for Trace Element Analysis', p. 151. J. A. Caruso, K. L. Sutton and K. L. Ackley Ed., Elsevier, New York, 2000.

6. S. P. Mendez, M. M. Bayon, E. B. Gonzalez and A. Sanz Medel, J. Anal. At. Spectrom., 14, 1333-1339, (1999).

7. C. Jorgelin, R. Wuillouda, A. Vonderheidea, J. Caruso, Spectrochimica Acta, 59B, 755-792 (2004).

8. H. Ge, X. J. Cai, J. F. Tyson, P. C. Uden, E. R. Denoyer, E. Block, Anal. Commun., 33, 279-287 (1996).

9. H. Cho, Y. Pak, J. of Kor. Chem. Soc., 55(3), 472-477
(2011).

10. A. Darrouzes and M. Potin-Gautier, Talanta, 75, 362368 (2008).

11. M. E. Moreno, C. Perez-Conde and C. Camara, J. Anal. Atom. Spectrom., 15, 681-693 (2000).

12. M. Johansson, G. Bordin and A. R. Rodriguez, Analyst, 125, 273-281 (2000)

13. M. Vilano and R. Rubio, J. Anal. Atom. Spectrom., 15, 177-185 (2000)

14. X. M. Guo, R. E. Sturgeon, Z. Mester and G. J. Gardner, Anal. Chem., 75, 2092-2100 (2003).

15. X. M. Guo, R. E. Sturgeon, Z. Mester and G. J. Gardner, Anal. Chem., 76, 2401-2408 (2004).

16. S. Simon, A. Barats, F. Pannier and Martine PotinGautier, Analytical and Bioanalytical Chemistry, 383(4), 562-569 (2005).

17. Y. Yin, J. Liu, G. Jiang, Trends in Anal. Chem., 30(10), 1672-1684 (2011). 